\title{
Comprehensive Contraceptive Education Intervention in a College Setting: Design and Methodology
}

\author{
Marian Evans $^{1 *}$, Breanna De Leon ${ }^{2}$, Reaghan Bathrick ${ }^{1}$, Annie Ricupero ${ }^{1}$ \\ ${ }^{l}$ Department of Public Health, Southern Connecticut State University, New Haven, CT, United States. \\ ${ }^{2}$ Department of Public Health, John Hopkins University, Baltimore, MD, United States.
}

Article Details
Article Type: Research Article
Received date: $11^{\text {th }}$ June, 2021
Accepted date: $09^{\text {th }}$ July, 2021
Published date: $22^{\text {nd }}$ July, 2021

Corresponding Author: Marian Evans, Assistant Professor, Department of Public Health, Southern Connecticut State University, United States. E-mail: evansm7@southernct.edu

Citation: Evans, M., De Leon, B., Bathrick, R., \& Ricupero, A. (2021). Comprehensive Contraceptive Education Intervention in a College Setting : Design and Methodology. J Pub Health Issue Pract 5(2): 181. doi: https://doi.org/10.33790/ jphip1100181

Copyright: (C2021, This is an open-access article distributed under the terms of the Creative Commons Attribution License 4.0, which permits unrestricted use, distribution, and reproduction in any medium, provided the original author and source are credited.

\begin{abstract}
Background: Unintended pregnancy continues to be a public health concern across the nation. National data demonstrates the highest rates of unintended pregnancy occurs in women who are 18 to 24 years old. Providing practical and meaningful health education about contraception has the potential to reduce unintended pregnancy and improve quality of life for young adults. This paper describes the design and methodology for a comprehensive contraceptive education intervention at a public university.
\end{abstract}

Methods: Convenience sampling was used with a custom survey conducted in Women's Health classes from 2015-2021. Surveys contained questions about demographic characteristics, knowledge of contraception options, sources of knowledge, stress levels, and confidence in knowledge. Students completed a pretest, received a comprehensive contraception health education lecture, and completed a post-test. Data collection was approved by the university's IRB, and analyses were conducted using SPSS Version 27.

Conclusion: At a time when reproductive freedom, choice, and justice is scrutinized and suppressed, it is imperative that young adults maintain and understand the importance of having control over when, where, and how they decide to have children if they desire to do so. There is a need for continued comprehensive health education and appropriate resources at the university level. The use of assessments, building trusted professor-student relationships, and exploring credible and reliable information sources can be used to reduce the number of unintended pregnancies for college-aged students. If significant, the replication of the design and methods could have a significant impact on the public health problem of unintended pregnancies, maternal health equity, and reproductive justice.

\section{Background/Introduction:}

Unintended pregnancy has continued to be a public health concern for more than 30 years. According to the Centers for Disease Control and Prevention [CDC] [1], unintended pregnancy is defined as “...a pregnancy that is reported to have been either unwanted (that is, the pregnancy occurred when no children, or no more children, were desired) or mistimed (that is, the pregnancy occurred earlier than desired)" (para 1). Reducing the percentage of unintended pregnancy has been an objective of the Healthy People publication since its first report in 1980 [2]. In 2011, the overall percentage of unintended pregnancy among all females of reproductive age (15-44 years old) was $45 \%$ [3]. National trend data from the National Survey of Family Growth (NSFG) show that unintended pregnancy rates have been higher for females in the age group of 18-24 years compared to those aged 15-17 years from 1981-2011 [3]. This higher prevalence of unintended pregnancy among females ages 18-24 years still exists today. These findings point to the need to provide resources and intervention to prevent unintended pregnancy in this specific female age group. One possible intervention strategy is prioritizing students who attend college [4,5]. With this somewhat captive audience, incidence and prevalence of unintended pregnancy have the potential to be reduced by providing education on contraception or birth control options.

Modern commercial birth control options have been available since 1912, with male condoms being one of the first contraceptive methods. Later in 1960, more effective methods such as the birth control pill and the intrauterine device (IUD) for women became available. Condoms and birth control pills are used more commonly and are less effective methods. More recently, in the $21^{\text {st }}$ century, a variety of other, more effective birth control options became available. For example, injectables, patches, vaginal rings, as well as long-acting reversible contraceptives (LARC), including IUDs (both hormonal and non-hormonal) and implants [6]. How effective a contraceptive method is can significantly reduce the risk of unintended pregnancy. The effectiveness of contraceptives is behavior-dependent and understood in two ways: (1) perfect use: is the method used correctly and consistently? and (2) typical use or failure rate: how effective is it in preventing pregnancy? [1]

On the one hand, the effectiveness of birth control methods such as condoms and pills are highly dependent on perfect use, and thus, the failure rate increases as perfect use decreases [1]. On the other hand, LARCs are highly effective, have very low failure rates, and have high perfect use. Their perfect use is a minimal factor after initial insertion because they do not usually require any other behavior until the end of their duration. Despite this, LARCs are the least commonly used birth control method by women $15-24$ years of age [1,6,7].

Behavior is an essential concept in understanding the college student population and age group. Risky sexual behaviors that are common on college campuses include: "anonymous sex, having sex with multiple partners, having sex while under the influence of alcohol or 
drugs, inconsistent use of condoms, and not engaging in dual-use..." [8], (pg. 2). One consequence of participating in risky sexual behavior is unintended pregnancy [8]. According to Bryant [9], "Unintended pregnancy is associated with increased risk for infant mortality, maternal mortality, pregnancy-related complications, low birth weight, and delayed prenatal care. The repercussions of unintended pregnancies include abortions, financial hardships, failure to reach educational goals, and dysfunctional parenting" (pg 13). This issue can be partially addressed by raising awareness and acceptance regarding the variety of birth control options available, including the newer and more effective LARCs. This study designed and implemented a survey to gauge knowledge and awareness regarding contraception among college students.

\section{Literature Review \\ Scope of the problem \\ Unintended pregnancy risks and burdens}

Birth control (contraception) is any method, medicine, or device used to prevent pregnancy [10]. The term "contraceptive" refers to the specific method or means of preventing pregnancy (e.g., condoms, birth control pills, IUD, withdrawal). Contraceptive use and effectiveness are significant factors in determining unintended pregnancy prevalence $[1,2]$. In recent decades (2000-present), there have been multiple contraceptive advancements in the United States $[6,11]$.

In a study that analyzed national trends in unintended pregnancy in 2011, the overall rate of unintended pregnancy for females aged 15 44 years was $45 \%$. For females ages 15-17, 18-19, 20-24, 25-29, 3034 , and $35-44$ years old, unintended pregnancy rates were $72 \%, 76 \%$, $59 \%, 42 \%, 31 \%, 34 \%$, respectively [3]. This data indicates, although the overall rate of unintended pregnancy is $45 \%$, females aged 15 24 years old have the highest unintended pregnancy percentage compared to other age groups. Many studies about contraceptive behaviors, as it pertains to unintended pregnancy specifically, have focused on devices or methods to prevent pregnancy [5,12-17]. It has been found that $43 \%$ of unintended pregnancy is due to the incorrect or inconsistent use of contraceptives [18]. Additionally, another 52\% of unintended pregnancy is due to contraceptive non-use [18].

Most contraceptive methods are female-centered in the U.S., and the burden of unintended pregnancy becomes the child bearer's responsibility [17]. According to Corbett et al. [19], "While an unplanned or unintended pregnancy has far-reaching psychological, physical, social, and financial ramifications for any woman, younger women are particularly vulnerable to the difficulties it creates" (p.161). According to multiple studies $[12,15,19]$, the subgroup of young college undergraduate women is of particular interest, not only because of their age, because of the unique challenges of parenthood and college requirements. Results from the National College Risk Behavior Survey indicate that $84 \%$ of college men and $88 \%$ of college women report having had sexual intercourse [15]. Increased sexual freedom, exploration, and new social experiences and situations make this an exciting but possibly daunting time for young adults. Since young men and women in their late teens and early twenties face a "higher risk" of unintended pregnancy, it is essential to understand the knowledge, attitudes, and behaviors of college students towards contraception. Moreover, data collected while young people are in college is important because it is at this time that sexual values and habits are explored and solidified [15].

\section{Contraceptive use factors}

As stated above, a large portion of unintended pregnancy is due to incorrect use, inconsistent use, or no use at all of the contraception methods [20]. Many factors affect contraceptive use, behaviors, and attitudes. Some factors that affect contraceptive use, including: cost; difficulty using or accessing contraceptives; infrequent sexual activity; mixed feelings about becoming pregnant; poor understanding of pregnancy risk; side effects; displeasure with available contraceptives; and availability of services and counseling about contraceptives, have been reported by women who want to avoid or delay pregnancy [18]. Compared to older women of reproductive age, teens aged 15-19 years old and young adults aged 20-24 years old have the highest proportions of contraceptive nonuse [7]. Furthermore, Bryant asserts [9] that, “...Eighty percent of college females are sexually active and not seeking to become pregnant... [and] College-age women between the ages of 20-24 have one of the highest rates of unintended pregnancies due to lack of contraceptive use and unsafe sexual practices" (p. 12). These studies point to the need for providing education about contraceptive options.

The prevalence of unintended pregnancy in the U.S. and are negative consequences is higher than any other developed country despite the availability of LARCs. Two possible reasons for this occurrence are: (1) the misinformation and lack of awareness regarding contraceptives, in general, and (2) fear associated with the use of LARCs [11,19,21].

Some of the oldest contraceptive methods remain the most widely used (i.e., condoms, the pill). The levels of knowledge about these less effective, older methods are higher, but inaccuracies remain and their use is riddled with myths $[13,19,22]$. Myths around topics of conception and LARCs [23] remain rampant. Although the pill and condoms are still the most commonly used birth control methods, the use of LARCs, specifically LARC-IUDs, has steadily increased between 2002 and 2013 [24]. And, the use of the more common birth control options has steadily declined from 2002 to 2013 [3,24].

\section{Overcoming contraceptive barriers (cost, access, and counseling)}

In the observational prospective cohort study called the CHOICE project [25], more than 9,000 women 14-45 years of age received contraceptive counseling that involved education about methods available from most to least effective, risks, benefits, and common side effects. After counseling, participants chose their birth control method, free of charge [26]. Participants were followed for two to three years, and study findings indicated that $75 \%$ of the women chose LARCs (IUD or implant). Furthermore, the study results found that participants who used LARC methods reported significantly higher continuation and effectiveness at one-, two-, and three-year follow-ups compared to participants who used non-LARC methods. The CHOICE project provides solid evidence that when barriers such as cost, lack of knowledge about contraceptive options and effectiveness, and healthcare providers' reluctance to offer or recommend LARCs are removed, LARCs are a great candidate to reduce unintended pregnancy [27]. LARCs are long-acting, meaning they can be used and are effective for years at a time. They require little work to maintain, are immediately reversible, highly effective at preventing pregnancy, and are a coital-independent form of contraception that can be used with other non-hormonal or barrier methods such as condoms (dual-use). Birth control pills and condoms do not provide various benefits in one method [2,24]. Moreover, women's contraceptive use and methods are likely to change over time, and LARCs can accommodate various lifestyles and preferences with essentially zero risks of unintended pregnancy.

Cost is a barrier to accessing the newer, more effective birth control methods such as LARCs. The high costs ranged from $\$ 500$ to $\$ 1,300$ until the company Medicine 360 produced Liletta. Liletta came to the US market in 2015 and was provided to safety-net providers at the cost of approximately $\$ 50$ [11]. It is the most affordable IUD with a smaller size and now lasts up to seven years. The more recent hormonal IUDs (Skyla, Kyleena) have been specially formulated for females who have not had children (nulligravid). The size of the IUD decreased, as did the amount of hormone.

Additionally, the hormonal distribution time for some IUDs has shortened. For example, Skyla in 2013; Liletta, in 2015, and 
Kyleena in 2016 all have shorter hormonal lives in comparison to Mirena. The alternative, Mirena, was explicitly designed for women who have had at least one child; consequently, it has a higher dose of the hormone levonorgestrel (LNG) and lasts seven years $[11,28]$.

Furthermore, women who are underinsured or uninsured might not be aware that there are options to get the more effective birth control methods such as LARCs at little or no cost. As of May 2018, 15 Title X facilities in the US, managed by Planned Parenthood of Southern New England (PPSNE) and Federally Qualified Health Centers (FQHC), offered access and lower-cost options for newer contraception options [29]. In another study, women desiring shortterm contraceptive options were offered more effective, long-lasting LARCs, and it was shown that use and continuation rates were significant [30]. The overwhelmingly preferred LARC was the IUD (as opposed to the implant), although no specific explanation was given for this finding [3,24]. Based on the National Health Statistics Report that looked at data between 2011 and 2013, it seems reasonable to conclude that LARCs are ideal for college-age women [2]. Lastly, another significant finding from the literature is that many healthcare providers tend to be behind in their current knowledge and training to provide adequate recommendations or counseling for LARCs [21].

In short, this review points to promising effects of LARCs, access at a reduced cost, and an increased ability to reduced unintended pregnancy.

According to the literature review and the authors' knowledge, there is no current national comprehensive assessment survey on contraception knowledge targeting college students between 18-24 years of age. Based upon all that has been shown for this age group and population, it seems prudent to make sure that contraception knowledge at the undergraduate college level is delivered effectively in a classroom setting. The last comprehensive assessment tool was published in 1976. It is more than forty years old and does not reflect new contraceptive methods made available in the past 20 years; it also includes contraceptive methods taken off the market [31]. The development of the current survey aimed to delineate misinformation, identify existing knowledge gaps, and increase awareness of newer contraceptive options, effectiveness, and safety.

\section{Methodology}

\section{Theoretical Background}

Multiple theories could have been ascribed to inform this study, such as the Health Belief Model (HBM) ; Theory of Planned Behavior (TPB) [32]; Precaution Adoption Process Model (PAPM) [33]; and Social Cognitive Theory (SCT) [34]. The PAPM was chosen because it is most closely aligned with the goals and objectives of this study and based on the literature review findings that college students aged 17 to 24 years of age were unaware or misinformed about birth control options [26]. PAPM operates on the premise that a typical college student is unaware of the variety of contraceptive options and therefore would not be able to decide to act on using an effective birth control method that works for their lifestyle and preferences [33].

PAPM is an intrapersonal-level theory that describes the seven stages that an individual goes through in deciding to act based on knowledge, beliefs, and motivation [35]. The two focal points of this theory are awareness/lack of awareness and action/inaction. Based on this theory, one possible barrier to action is the lack of awareness. If individuals are made aware of something, they can then decide to act on this newly acquired knowledge. In this study, if a college student is aware of the variety of contraceptive options, how they are used, and their associated effectiveness, then they might be more likely to decide to use a contraception method with a high degree of effectiveness according to the theory [35].

The seven stages of the PAPM, in order, are 1) Unaware; 2) Unengaged; 3) Deciding About Acting; 4) Deciding Not to Act; 5)
Deciding to Act; 6) Acting; and 7) Maintenance [35]. This study aims to move an individual from unaware/not knowledgeable about the birth control options and unengaged to a state where they decide to act. These aims will be accomplished by offering students information about more effective contraceptive methods (i.e., LARCs) and encouraging students to talk to a trusted individual(s)/organization(s) with factual information regarding contraceptive options if this is not already occurring.

\section{Sample Description \\ Participants \\ Population and Sampling}

This quasi-experimental study took place at a public, urban university campus in the northeast US. During the years of this study (2005-2020), the campus enrolled approximately 10,000 students. $80 \%$ received some type of financial aid, and $40 \%$ of the full-time undergraduate student population identified as non-white.

\section{Instrumentation Development/Survey Description}

\section{Survey Design}

Custom survey questions were created to assess knowledge about contraception options and students' level of confidence in their knowledge. These questions were developed by the principal investigator, validated through a group of three content experts, and pilot-tested on a subset of sample participants.

The survey was developed in two sections to reflect the three major findings of the literature review: 1) Contraceptive knowledge among college students is subpar; and students tend to know more about the commonly used birth control methods (i.e., the pill and condoms) than other methods of birth control $[13,14,19]$; 2) LARCs are the most effective contraceptive method available, but a majority of college-age students have not considered or are unaware of this type of method [7,24,30,36,37] 3) Demographics such as age, socioeconomic status, race, education, and other social determinants of health can affect awareness and access to LARCs [11,21].

The first rendition of the survey was designed to serve two purposes: (1) to identify contraception topics that are poorly understood among the college student population and (2) to identify gaps in knowledge or awareness of specific contraception methods. The survey contained six demographic questions, ten contraception questions, and one awareness question for a total of seventeen questions. The types of questions included were multiple-choice, fill in the blank, and select all that apply. Students were asked to write in their class and section, date, age (in number format), and grade in college for the six specific demographic questions. Students were asked to select answers about gender (male, female, other); race/ethnicity (African American/Black, Hispanic/Latinx, Caucasian, Other, Two or More Races); marital status (married, single, divorced, and other); and children status (yes or no). Key demographic indicators were included to compare differences between groups. This section is key to collecting data and comparing different groups.

For the rest of the survey, the questions covered the following themes: access and availability (prescription, over the counter); knowledge of various birth control methods; emergency contraception; mechanism of actions (barrier, hormonal, long-acting, reversal, and permanent); awareness of older versus newer methods; IUD knowledge and availability; historical perspective of contraception; and level of confidence in knowledge regarding birth control methods. A revision to the survey took place in 2019 , the revision incorporated and addressed early sources of contraceptive information, measuring students' level of confidence in that knowledge and perceived stress experienced based on their contraception knowledge.

The average time for students to complete the survey was 10 to 25 minutes. The survey was tested for user-friendliness, readability, 
content, organization, and timing. To assign a reading level to the survey, the Simple Measure of Gobbledygook (SMOG) readability formula was used. The SMOG reading grade for the survey was determined to be at the $10^{\text {th }}$-grade level [38]. Studies show that a $6^{\text {th }}$ grade or lower reading level is acceptable for the general public but a $10^{\text {th }}$-grade reading level is acceptable for college students.

\section{Sexual and Reproductive Health Education}

Students received continuous sexual and reproductive health education on other sexual and reproductive health topics throughout the Women's Health course. If and when a question arose concerning contraception during the semester it was answered but the students were told that a more lengthy and in-depth class session would be devoted to just contraception. Students were encouraged to write down their questions as well, in order to remember them for the session on contraception. The instructor is a trained healthcare professional that has taught the class since 2005 both in person and virtual lecture sessions. Due to Covid-19 the survey format was delivered electronically starting in the Fall of 2020.

\section{Data Collection and Analysis}

Data collection was approved by the university's Institutional Review Board. Data were collected from a convenience sample of undergraduate students in a regularly scheduled Women's Health class during both the fall and spring semesters from 2015 to 2021. The Women's Health course was cross-listed and offered through the Department of Public Health and the Women's and Gender Studies program. Several measures were taken to ensure anonymity: students placed their own completed surveys in data collection envelopes, anonymous survey links and no individual identifying data was collected.

\section{Data Analysis Procedures}

Completed surveys were scored and entered into a secure EXCEL database and converted into data files for analysis using SPSS version 27. Data were cleaned before analysis: Descriptive statistics were estimated (counts and percentages for categorical variables, means, and standard deviations for continuous and normally distributed variables). The analytic plan performed sample t-tests as well as means, frequencies, and percentages, all using Excel and SPSS. These tests were used to determine the effectiveness of the health education on student contraception knowledge, confidence in knowledge, and contraception awareness.

\section{Discussion}

This paper described the design and methodology of a quasiexperimental study of contraception methods knowledge, sources of contraception knowledge, self-efficacy in knowledge, and levels of stress concerning contraception knowledge and gaps, determined by a pre-test, intervention, and post test design of participants enrolled in a Women's Health course at a public university in the Northeast United States. The health education intervention was employed to help participants acquire contraception knowledge, confidence in knowledge, decrease stress around their knowledge, and awareness. A comprehensive contraceptive education intervention will provide a replicable model for targeting the public health problem of unintended pregnancy among 18 to 24 year olds in college settings. If demonstrated effective this intervention has potential for high impact.

This study has some limitations, since it was not possible to blind study participants, it is possible participants acquired knowledge prior to the intervention session. Perhaps the most notable limitation include self-selection bias as participation was voluntary and could not be selected in a random manner. Participants that were interested in the topic or had questions concerning contraception methods might have been more interested in participating in the study. Our recruitment was pool were participants that responded to the survey. During and prior to dissemination of survey ample opportunities were given to participants to ask and have questions answered.
Lastly, due to the nature of the study follow-up of participants was not part of the study. These limitations were minimized by collecting data over seven years and allowing students from any department to enroll in the course.

Despite these limitations, this study provided insights on gaps in contraception knowledge for participants enrolled in the Women's Health course. This study highlighted the need for more education about contraception options in classroom settings at the college level as they are at a critical age in their reproductive years. The demonstrated effectiveness of LARCs and a current trend of increasing LARC access to young adult and nulliparous women points to the increased need for college students to be aware of this useful information and reduce unintended pregnancy incidence in this population ultimately. Future potential recommendations for this study would be:

1. Further revision and testing of the survey and intervention,

2. Lesson plan and manual for future comprehensive education outside of the Women's Health classroom,

3. Data collection and trend identification and additional gaps in knowledge;

4. Publish significant findings (results paper) in an appropriate peer-reviewed journal;

5. Additional mixed-method survey that captures qualitative data in the future

6. Future study on men's contraception knowledge, attitude, and behaviors

7. Future participants and implementation in other disciplines (nursing, healthcare studies, health sciences, etc..)

It is the intention that the intervention could be refined to be used to develop a comprehensive assessment that would be accepted statewide or nationally in the future to assess the current contraception knowledge and confidence of college students concerning contraception methods. Based on the use and findings of the more comprehensive assessment, sexual health education can be tailored to college students that fall within the age groups with the highest level of unintended pregnancies. From a public health perspective, 18-24-year-old females' ability to better determine their agency around reproduction decisions is crucial in this current political environment. At a time when reproductive freedom, choice, and justice are scrutinized and suppressed, it is imperative that young adults maintain and understand the importance of having control over when, where, and how they decide to have children if they desire to do so. This study has the potential for dissemination, replication, and sustainability. The use of assessments, building trusted professorstudent relationships, and effective lesson planning can be used to reduce the number of unintended pregnancies for college-aged students. This is a timely study that has real-world public health policy and practice implications.

Competing Interests: The author declares no competing interests.

\section{References}

1. Centers for Disease Control and Prevention. (2017). Unintended Pregnancy Prevention. Retrieved from www.cdc.gov: https:// www.cdc.gov/reproductivehealth/UnintendedPregnancy/index. htm

2. Daniels, K., Daugherty, J., Jones, J., \& Mosher, W. (November 10, 2015). Current Contraceptive Use and Variation by Selected Characterstics Among Women Aged 15-44: United States, 20112013, Number 86. National Health Statstics Reports.

3. Finer, L. B., \& Zolna, M. R. (2016). Declines in Unintended Pregnancy in the United States, 2008-2011. The New England Journal of Medicine, 843-846. 
4. Brener, N. D., \& Gowda, V. R. (2001). US College Students' Reports of Receiving Health Information on College Campuses. Journal of American College Health, 223-228.

5. Morrison, L. F., Sieving, R. E., Pettingell, S. L., Hellerstedt, W. L., McMorris, B. J., \& Bearinger, L. H. (2015). Protective Factors, Risk Indicators, and Contraceptive Consistency Among College Women. Journal of Obstetric, Gynecologic, and Neonatal Nursing, 155-164.

6. Daniels, K., Mosher, W., \& Jones, J. (2013). Contraceptive Methods Women Have Ever Used: United States, 1982-2010. National Health Statstics Reports.

7. Kavanaugh, M. L., Jerman, J., Ethier, K., \& Moskosky, S. (2012). Youth-Friendly and Long-Acting Reversible Contraceptive Services in US Family Planning Facilities. Journal of Adolescent Health, 285.

8. Turchik, J. A., \& GIdycz, C. A. (2012). Prediction of Sexual Risk Behaviors in College Students Using the Theory of Planned Behavior: a Prospective Analysis. Journal of Social and Clinical Psychology, 1-27.

9. Bryant, K. D. (2009). Contraceptive Use and Attitudes Among Female College Students. The ABNF Journal, 12-13.

10. Office of Women's Health, HHS. (n.d.). Birth Control Methods. Retrieved from Womenshealth.gov: https://www.womenshealth. gov/a-z-topics/birth-control-methods

11. Henry J Kaiser Family Foundation. (2016, Novemeber 2). Intrauterine Devices (IUDs): Access for Women in the U.S. Retrieved from www.kff.org: https://www.kff.org/womenshealth-policy/fact-sheet/intrauterine-devices-iuds-access-forwomen-in-the-u-s/

12. Brunner-Huber, L. R., \& Ersek, J. L. (2009). Contraceptive Use among Sexually Active University Students. Journal of Women's of Health, 1063-1069.

13. Frost, J. J., Lindberg, L. D., \& Finer, L. B. (2012). Young Adults' Contraceptive Knowledge, Norms and Attitudes: Associations with Risk Of Unintended Pregnancy. Perspectives on Sexual and Reproductive Health, 107-112.

14. Laganá, L. (1999). Psychosocial Correlates of Contraceptive Practices During Late Adolescence. Adolescence, 464.

15. Pluhar, E. I., Frongillo, E. A., Stycos, J. M., \& DempsterMclain, D. (2003). Changes Over Time in College Students' Family Planning Knowledge, Preference, and Behavior and Implications for Contraceptive Education and Prevention of Sexually Transmitted Infections . College Student Journal, 421.

16. Sutton, J. A., \& Walsh-Buhi, E. R. (2017). Factors influencing college women's contraceptive behavior: An application of the integrative model of behavioral prediction. Journal of American College Health, 339-347.

17. Whitley, B. E. (1990). College Student Contraceptive Use: Multivariate Analysis. Journal of Sex Research, 305-313.

18. Jeana H. Frost, Zoë Chance, Michael I. Norton, Dan Ariely(2008).People are experience goods: Improving online dating with virtual dates,22(1),Journal of Interactive Marketing. https://doi.org/10.1002/dir.20106

19. Corbett, P. O., Mitchell, C. P., Taylor, J. S., \& Kemppainen, J. (2006). Emergency contraception: Knowledge and perceptions in a university population. American Academy of Nurse Practioners, 161-165.

20. Centers for Disease Control and Prevention. (2017). Contraception. Retrieved from www.cdc.gov: https://www.cdc. gov/reproductivehealth/contraception/index.htm\#44

21. Strasser, J., Borkowski, L., Couillard, M., Allina, A., \& Wood, S. (2016). Long-Acting Reversible Contraception: Overiew of ResearchandPolicyin United States. DistrictofColumbia:George Washington University, Jacob's Institue of Women's Health.
22. Sutton, J. A., \& Walsh-Buhi, E. R. (2017). Factors influencing college women's contraceptive behavior: An application of the integrative model of behavioral prediction. Journal of American College Health, 339-347.

23. Black, K., Lotke, P., Buhling, K. J., \& Zite, N. B. (2012). A Review of Barriers and Myths Preventing the More Widespread Use of Intrauterine Contraception in Nulliparous Women. European Journal of Contraception and Reproductive Health Care, 17, 340-350. doi:10.3109/13625187.2012.700744

24. Branum, A. M., \& Jones, J. (Feburary 2015). Trends in LongActing Reversible Contrraception Use Among Women Aged 15-44, Number 188. National Center for Health Statistics.

25. Peipert, J., Madden, T., Allsworth, J. E., \& Secura, G. M. (2012). Preventing Unintended Pregnancies by Providing NoCost Contraception. Obstetrics and Gynecology, 1291-1297.

26. Birgisson, N. E., Zhao, Q., Secura, G. M., Madden, T., \& Peipert, J. F. (2015). Preventing Unintended Pregnancy: The Contraceptive CHOICE Project in Review. Journal of Women's Health, 349-353.

27. Secura, G. M., Allsworth, J. E., Madden , T., Mullersman, J. L., \& Peipert, J. F. (2010). The Contraceptive CHOICE project: reducing barriers to long-acting reversible contraception. American Journal of Obstetris and Gynecology, 115e1-7.

28. Bedsider.org. (2019, May 30). Bedsider. Retrieved from Bedsider.org.

29. Office of Population Affairs. (2018, May). Retrieved from Title X Family Planning: https://www.hhs.gov/opa/sites/default/files/ Title-X-Family-Planning-Directory-May2018.pdf

30. Hubacher, D., Spector, H., Monteith, C., Chen, P.-L., \& Hart, C. (2017). Long-Acting Reversible Contraceptive Acceptability and Unintended Pregnancy Among Women Presenting for Short-Acting Methods: A Randomized Patient Preference Trial. Journal of Obstertrics and Gynecology, 101, 104, 106.

31. Haynes, M. C., Ryan, N., Saleh, M., Winkel, A. F., \& Ades, V. (2017). Contraception Knowledge Assessment: Validity and Reliabilty of a Novel Contraceptive Research Tool. Contraception, 190-197.

32. Reinecke, J., Schmidt, P., \& Ajzen, I. (2006). Birth control versus AIDS prevention: A Hierarchial Model of Condom Use Among Young People. Journal of Applied Social Psychology, 743-59.

33. Glanz, K., Rimer, B. K., \& Viswanath, K. (2008). Health Behavior and Health Education: Theory, Research, and Practice. San Francisco: Jossey-Bass Pbulishers.

34. Bandura, A. (1989). Regulation of cognitive processes through perceived self-efficacy. Developmental Psychology, 729-735.

35. National Institute of Health. (2005, September). Theory at a Glance: A Guide to Health Promotion Practice, 2nd Edition. Bethesda, Maryland, United States of America: National Institute of Health.

36. American College of Obstreticians and Gynecologists. (November 2017). ACOG Practice Bulletin: Long-Acting Reversible Contraception, Implants and Interuterine Devices, Number 186. American College of Obstreticians and Gynecologists.

37. Diedrich, J. T., Klein, D. A., \& Peipert, J. F. (2017). LongActing Reversible Contraception in Adolescents: A Systematic Review and Meta-Analysis. American Journal of Obstetrics and Gynecology, 364,372.

38. Mc Laughlin, G. H. (1969). SMOG Grading-a New Readability Formula . Journal of Reading, 636-646. 